\title{
PENGARUH GAYA KEPEMIMPINAN DAN KOMITMEN KARYAWAN TERHADAP PRODUKTIVITAS KERJA KARYAWAN PADA PT. KUNANGO JANTAN
}

\author{
1) SALFADRI, Dosen FE Unes, Salfadri syamsudin@gmail.com \\ 2) NOVA BEGAWATI , Dosen FE Unes Begawati@gmail.com \\ 3) ARMEDI TRI ANDRI, Mahasiswa FE Unes, armeditriandri@gmail.com
}

\begin{abstract}
ABSTRAC
Work productivity means achievement which means the results of the work achieved, and carrying out an activity that aims to get results. PT. Kunango Jantan is a company that processes raw materials into finished goods, this company processes heavy equipment such as PLN poles with concrete bridges, in carrying out its operations PT. Kunango Jantan requires workers to process these products because work does require human strength. The research objective was to determine the influence of leadership style and employee commitment to employee work productivity at PT. Male Kunango. The types of data are primary. The population of this study were all office employees at PT. Kunango Males as many as 61 people. And sample 61 people. Data analysis method used is multiple linear regression analysis. The results of the study found that there was an influence of leadership style variables and employee commitment to influence together the work productivity of employees of PT. Male Kunango either partially or smultan.
\end{abstract}

Keywords: leadership style, commitment of employee and work productivity

\section{ABSTRAK}

Produktivitas kerja mengandung makna prestasi yang berarti hasil karya yang dicapai, dan melakukan suatu kegiatan yang bertujuan mendapatkan hasil. PT. Kunango Jantan merupakan perusahaan yang mengolah bahan mentah menjadi barang jadi, perusahaan ini mengolah alat-alat berat seperti tiang PLN sama beton jembatan, dalam melakukan operasionalnya PT. Kunango Jantan memerlukan tenaga kerja dalam mengolah produks tersebut karena pekerjaan memang memerlukan ntenaga manusia. Tujuan penelitian adalah untuk mengetahui pengaruh gaya kepemimpinan dan komitmen karyawan terhadap produktivitas kerja karyawan pada PT. Kunango Jantan. Jenis data adalah data primer. Populasi penelitian ini adalah seluruh karyawan kantor pada PT. Kunango Jantan sebanyak 61 orang.dan sampel 61 orang. Metode analisis data yang digunakan adalah analisis regresi linear berganda. Hasil penelitian ditemukan ada pengaruh variabel gaya kepemimpinan dan komitmen karyawan berpengaruh bersama-sama terhadap produktivitas kerja pegawai PT. Kunango Jantan baik secara parsial maupun smultan.

Kata Kunci : gaya kepemimpinan, komitmen keryawan dan produktivitas kerja 


\section{PENDAHULUAN}

Produktivitas kerja mengandung makna prestasi yang berarti hasil karya yang dicapai, dan melakukan suatu kegiatan yang bertujuan mendapatkan hasil. Produktivitas kerja merupakan patokan akhir dari usaha yang dilakukan oleh pegawai dalam pelaksanaan tugasnya dan kinerja yang tinggi mengambarkan keberhasilan dan kesuksesan pengawai/pegawai dalam pelaksanaan tugas dan tanggung jawab yang dibebankan kepadanya serta sebaliknya kinerja yang rendah menggambarkan ketidakberhasilan dan ketidaksuksesan pegawai dalam pelaksanaan tugas dan tanggung jawab yang dibebankan kepadanya.

Bagus tidaknya produktivitas kerja seseorang dapat dilihat dari hasil kerjanya, pegawai merupakan orang yang lengsung bergerak di dunia pendidikan yang memegang peranan penting dalam kehidupan suatu bangsa, karena pendidikan itu dapat mewariskan budaya kepada generasi penerusnya berupa pengetahuan, keterampilan, sikap dan nilai. Pendidikan dapat membentuk manusia seutuhnya dalam arti luas bahwa pegawai dapat melaksanakan suatu proses perluasan pandangan hidup dan pengembangan keterampilan peserta didiknya. Selain itu pegawai pendidikan disamping mentransfer budaya juga berorientasi kepada masa depan dengan memperhatikan tuntuntan kamajuan zaman yang ditandai dengan persaingan.

Tujuan utama dari peningkatan produktivitas kerja pegawai adalah agar pegawai baik ditingkat bawah maupun ditingkat atas mampu menjadi pegawai yang efisien, efektif dan profesionalisme dalam bekerja. Seorang pegawai yang produktif adalah pegawai yang cekatan das 1 l menghasilkan barang atau jasa sesuai mutu yang ditetapkan dan waktu yang lebih singkat, sehingga akhirnya dapat tercapai tingkat produktivitas kerja pegawai yang tinggi.
Pada bahagian lain Discenza dan Smith dalam Fathony (2013:32) mengemukakan bahwa faktor-faktor umum yang mempengaruhi produktivitas kerja meliputi dimensia Individu (yaitu kemampuan, prestasi, motif, sasaran, kebutuhan dan nilai) ; suasana motivasi dan kompensasi, kepuasan kerja, komitmen kerja, kemimpinan, demensia kelompok (yaitu, status, norma, keeratan dan iklim komunikasi serta struktur perusahaan termasuk unsur-unsur makro dalam pengendalian dan perencanaan).

Banyak faktor yang mempengaruhi produktivitas kerja karyawan salah satunya gaya kepemimpinan dan komitmen karyawan. Peran pemimpin disuatu organisasi sangat dominan meskipun demikian seorang pemimpin tidak boleh mengabaikan peranan pekerja sebagai pelaksana berbagai macam pekerjaan dan tugas untuk mencapai tujuan perusahaan. Untuk itu seorang pemimpin harus terus menerus mendorong dan memotivasi karyawan sehingga karyawan dapat berprestasi. Kemepimpinan yang efektif sangat penting untuk kelangsungan hidup dan keberhasilan sebuah organisasi.

Selain gaya kepemimpinan faktor lain yang memberikan kontribusi terhadap produktivitas kerja adalah komitmen kerja karyawan. Menurut Sapeni (2013:88) tinggi rendahnya komitmen karyawan tentu ada faktor yang mempengaruhi terhadap hal demikian, komitmen karyawan selain tumbuh rasa kepedulian seseorang terhadap suatu tugas dan kepentingan umum dan organisasi, bukan saja karena atas kepentingan pribadi, akan memberi kontribusi terhadap komitmen. Komitmen karyawan terhadap organisasi terdiri-dari komitmen efektif, komitmen berkelanjutan dan komitmen normatif.

Penelitian tentang Pengaruh berbagai variabel terhadap produktivitas kerja telah banyak dilakukan, yang dilakukan oleh Jana 
Susila (2014) mengenai Pengaruh kepemimpinan dan budaya kerja terhadap produktivitas kerja Karyawan Pada Bagian Tenaga Penjualan UD Surya Raditya Negara. Hasil penelitiannya menunjukkan bahwa secara simultan dan parsial gaya kepemimpinan dan komitmen organisasi berpengaruh terhadap produktivitas kerja. Penelitian lain yang dilakukan oleh Lestari (2015 : 23-30) yang meneliti tentang Pengaruh Gaya Kepemimpinan Terhadap produktivitas kerja Karyawan (Studi Pada Koperasi Pegawai Negeri). Hasil penelitian menunjukkan bahwa secara simultan dan parsial gaya kepemimpinan berpengaruh terhadap produktivitas kerja karyawan.

PT. Kunango Jantan merupakan perusahaan yang mengolah bahan mentah menjadi barang jadi, perusahaan ini mengolah alat-alat berat seperti tiang PLN sama beton jembatan, dalam melakukan operasionalnya PT. Kunango Jantan memerlukan tenaga kerja dalam mengolah produks tersebut karena pekerjaan memang memerlukan ntenaga manusia.

Rendahnya produktivitas kerja karyawan pada PT. Kunango Jantan terlihat pada capaian hasil produksi selama tahun 2017 yaitu :

\section{Tabel 1 : Target dan Realisasi Hasil Produksi PT. Kunango Jantan (1 Januari -31 Desember 2017}

\begin{tabular}{|c|c|c|}
\hline Bulan & Target & Realisasi \\
\hline Januari & 150 & 145 \\
Februari & 163 & 155 \\
Maret & 167 & 160 \\
April & 171 & 168 \\
Mei & 174 & 170 \\
Juni & 177 & 172 \\
\hline
\end{tabular}

\begin{tabular}{|c|c|c|}
\hline Juli & 178 & 175 \\
Agustus & 180 & 177 \\
September & 185 & 180 \\
Oktober & 188 & 186 \\
November & 190 & 188 \\
Desember & 200 & 190 \\
\hline
\end{tabular}

Sumber : PT. Kunango Jantan, 2018

Berdasarkan tabel 1.1 di atas terlihat selama satu tahun terakhir terhitung dari bulan Januari - Desember 2017, dimana selama tahun terakhir realisasi tidak mencapai target. Hasil wawancara peneliti dengan Bapak Sawirman selaku kepala personalia pada PT. Kunango Jantan pada tanggal 16 Desember 2017, hasil wawancara memperlihatnya masih rendahnya produktivitas kerja karyawan dalam bekerja hal ini terlihat dari kuantitas kerja karyawan dalam beberapa bulan terakhir tidak mencapai target selain itu dari segi kualitas. Masalah lain yang terlihat berkenaan dengan gaya kepemimpinan adalah dimana pimpinan dalam menjalankan tupoksinya bertindak secara otoriter karena karyawan yang diberi kedudukan hanya yang memiliki hubungan dengan pimpinan. Sedangkan berkenaan dengan komitmen keryawan terlihat permasalahan dimana karyawan tidak komitmen dalam menjalankan tugasnya.

Tujuan penelitian ini adalah :

1. Untuk mengetahui dan menganalisis apakah gaya kepemimpinan berpengaruh terhadap produktivitas kerja karyawan pada PT. Kunango Jantan.

2. Untuk mengetahui dan menganalisis apakah komitmen karyawan berpengaruh terhadap produktivitas 
kerja karyawan pada PT. Kunango Jantan.

3. Untuk mengetahui dan menganalisis apakah gaya kepemimpinan dan komitmen karyawan berpengaruh terhadap produktivitas kerja karyawan pada PT. Kunango Jantan.

\section{Gaya Kepeminpinan}

Menurut Wibowo (2014: 66) kepemimpinan pada prinsipnya merupakan kemampuan seseorang pemimpin dalam menggerakkan organisasi, dengan segala sumberdaya yang ada untuk mencapai tujuan. Kepemimpinan adalah setiap perbuatan yang dilakukan oleh individu atau kelompok untuk mengkoordinasi dan memberi arah kepada individu atau kelompok yang tergabung di dalam wadah tertentu untuk mencapai tujuan yang telah ditetapkan sebelumnya.

Berdasarkan teori yang dikemukakan oleh Orlando dan James MC.Fallen dalam Wahjusumidjo (2014: 44) indikator dari gaya kepemimpinan adalah :

a. Empati

Adalah kegiatan berfikir individu mengenai "rasa" yang dia hasilkan ketika berhubungan dengan orang lain. Pemimpin yang memiliki emapti yang tinggi pasti memiliki hubungan yang baik anggotanya. Jika pimpinan yang memiliki empati yang baik maka dia akan mempertimbangkan pendapat anggotanya sehingga dihasilkan keputusan yang bijak dan adil.

b. Menjelaskan misi yang menarik

Pimpinan sebagai juru bicara untk visi harus mengkomunikasikan suatu pesan yang mengikat sama orang agar melibatkan diri dan menyentuh visi organisasi secara internal. Dan ekternal. Visi yang disampaikan harus bermanfaat, menarik dan menimbulkan kegairahan dimasa depan organisasi yang merupakan cara pimpinan menjelaskan tujuan organisasi ke bawahan.

c. Keyakinan diri Merupakan kemampuan pimpinan dalam menunjukan sikap meyakinkan kepada bawahan. Sikap yang ditunjukan oleh pimpinan saat dia merasa cukup tahu dan menyimpulkan bahwa dirinya telah mencapai ketenaran. Karena keyakinan merupakan suatu sikap, maka keyakinan seseorang tidak selalu benar.

d. Meningkatkan image

Merupakan cara pimpinan meningkatkan citra nya kepada bawahan. Citra diri seseorang terbentuk dari perjalanan pengalaman masa lalu, keberhasilan dan kegagalan, pengetahuan yang dimilikinya dan bagaimana orang lain telah menilai secara subjektif.

e. Yakin dengan kemmpauan pengikut

Merupakan pimpinan yang mengakui kemampuan bawahan dimana akan kemampuan dan kesadaran bawahan sehingga pemimpin tidak menaruh perhatian terhadap tugas yang diberikan

f. Memberikan peluang untuk sukses, merupakan kesempatan yang diberikan oleh pimpinan kepada bawahan untuk sukses.

\section{Komitmen Keryawan}

Menurut $\begin{gathered}\text { Robbins } \\ \text { komitmen } \\ \text { karyawan }\end{gathered}$ merupakan
kecenderungan dalam diri seseorang untuk
merasa terlibat aktif dengan penuh tanggung
jawab. Peran aktif dengan penuh rasa
tanggung jawab yang dimiliki oleh pegawai,


maka akan mendorongnya terjun langsung dalam suatu kegiatan, harus sanggup menetapkan keputusan untuk dirinya sendiri dan dilaksanakan dengan sebaiknya. Karena komitmen merupakan suatu keputusan atau perjanjian seseorang dengan dirinya sendiri untuk melakukan atau tidak melakukan, berhenti atau meneruskan sesuatu kegiatan, maka personil telah memiliki satu dari beberapa alternatif yang dianggap baik, tidak ragu-ragu dalam mengambil sikap.

\section{Indikator Komitmen Karyawan}

Menurut Robins (2013 : 55) komitmen karyawan adalah kepedulian terhadap tugas dan pekerjaan yang diberikan oleh pimpinan, serta bagaimana seorang pegawai mempetanggung jawabkan tugasnya tersebut. Menurut Robins (2013 : 55) indikator pengukuran komitmen karyawan adalah :

a. Sikap terhadap tugas adalah bagaiaman sikap pegawai terhadap tugas yang diberikan kepadanya

b. Loyalitas adalah bagaimana loyal pada pekerjaannya

c. Tanggung jawab adalah tanggung jawab atas tugas yang diberikan kepada pegawai

d. Disiplin dalam bekerja adalah bagaimana pegawai dalam memilah waktu bekerja.

\section{Produktivitas Kerja}

Menurut Hasibuan

(2014:125)

"Produktivitas mengandung sikap mental yang selalu berpandangan bahwa kehidupan hari ini harus lebih baik dari kemarindan esok lebih baik dari hari ini". Produktivitas secara umum diartikan sebagai hubungan antara keluaran (barang dan jasa) dengan masukan (tenaga kerja, bahan, uang).Produktivitas adalah ukuran efisiensi produktif. Suatu perbandingan antara hasil keluaran dan masukan. Masukan sering dibatasi dengan tenaga kerja, sedangkan keluaran diukur dalam kesatuan fisik, bentuk dan nilai (Wirawan, 2013).
Indikator Produktivitas Kerja

Indikator produktivitas kerja

sebagaimana menurut Flippo (1990) dalam Mas'ud (2013: 33) :

a. Kualitas kerja adalah hasil kerja yang dilakukan oleh pegawai.

b. Kuantitas kerja adalah banyaknya pekerjaan yang bisa diselesaikan oleh pegawai dengan baik

\section{Hipotesis}

1. Diduga ada pengaruh signifikan gaya kepemimpinan terhadap produktivitas kerja karyawan pada PT. Kunango Jantan

2. Diduga ada pengaruh signifikan komitmen karyawan terhadap produktivitas kerja karyawan pada PT. Kunango Jantan

3. Diduga ada pengaruh signifikan gaya kepemimpinan dan komitmen karyawan terhadap produktivitas kerja karyawan pada PT. Kunango Jantan

\section{METODE PENELITIAN}

Penelitian dilaksanakan di PT. Kunango Jantan. Dalam pengumpulan data peneliti mengumpulkan data dalam dua metode yaitu: Penelitian Lapangan (Field Research dan Penelitian Kepustakaan (Library Research). Untuk mengumpulkan data informasi yang diperlukan dalam penelitian ini,teknik yang digunakan penulis anatara lain: Observasi, Wawancara (Interview), Kuesioner, dan studi Pendahuluan merupakan survei awal yang peneliti lakukan ke lapangan. Pada

penelitian ini data yang akan digunakan terdiri-dari dua jenis antara lain data kuantitatif dan data kualitatif, lebih lanjut dapat dijelaskan sebagai berikut : (1) 1. Data Kualitatif adalah data untuk melihat gambaran masing-masing variabel, (2) 2. Data Kuantitatif adalah data untuk melihat hubungan antara dua variabel yaitu variabel 
independen dan variabel dependen. Sumber data dalam penelitian ini adalah data primer dan data sekunder. Populasi penelitian ini adalah seluruh karyawan kantor pada PT. Kunango Jantan sebanyak 61 orang, sampel 61 orang. Data yang digunakan adalah data primer dan data sekunder. Metode analisis yang digunakan adalah analisis regresi linear berganda.

\section{HASIL DAN PEMBAHASAN}

\section{Analisis Dekriptif}

1. skor rata-rata variabel gaya kepemimpinan pada PT. Kunango Jantan. yang terdiri-dari 30 pertanyaan, dimana nilai rata-rata 3,46 dengan Tingkat Capaian Responden (TCR) sebesar 69,11\%. Hal ini menunjukan bahwa variabel gaya kepemimpinan pada PT. Kunango Jantan. dalam kategori Baik.

2. skor rata-rata variabel komitmen karyawan pada PT pada PT. Kunango Jantan. yang terdiri-dari 20 pertanyaan, dimana nilai rata-rata 3,64 dengan Tingkat Capaian Responden (TCR) sebesar 72,70\%. Hal ini menunjukan bahwa variabel komitmen karyawan pada PT. Kunango Jantan. dalam kategori Baik.

3. skor rata-rata variabel produktivitas kerja pada PT. Kunango Jantan. yang terdiri-dari 20 pertanyaan, dimana nilai rata-rata 3,53 dengan Tingkat Capaian Responden (TCR) sebesar 70,54\%. Hal ini menunjukan bahwa variabel produktivitas kerja pada PT. Kunango Jantan. dalam kategori Baik.

\section{Uji Asumsi Klasik}

\section{Uji Normalitas}

nilai Asym.Sig (2-tailed) untuk variabel produktivitas kerja (Y) 0,652, variabel gaya kepemimpinan $\left(\mathrm{X}_{1}\right)$ sebesar 0,333 , variabel komitmen karyawan $\left(\mathrm{X}_{2}\right)$ sebesar 0,467 dari semua variabel penelitian nilainya lebih besar dari tingkat signifikan yang digunakan pada penelitian ini $(\alpha=0,05)$. Dengan demikian dapat disimpulkan bahwa semua variabel penelitian berdistribusi normal, dengan demikian analisis regresi linear berganda dapat dilaksanakan karena data telah berdistribusi normal

\section{Uji Multikolonieritas}

hasil olahan data untuk uji multikolonieritas sebagaimana terlihat pada Tabel 4.12 di atas diketahui bahwa nilai tolerance dari Collinearity Statistics mendekati 1 (satu) dan nilai VIF (Variance Inflation Factor) untuk semua variabel bebas di bawah 10 (sepuluh). Hal ini menunjukkan bahwa tidak hubungan yang berarti antara sesama variabel bebas. Oleh karena itu dapat disimpulkan bahwa data hasil penelitian ini tidak mengalami kasus multikolinearitas sehingga pengolahan data dengan regresi linear berganda dapat karena tidak terdapat kasus multikolinearitas antara sesama variabel bebas

\section{Nilai Hetekesdositas}

nilai sig untuk variabel gaya kepemimpinan 1,000 dan untuk komitmen sebesar 1,000 maka dapat disimpulkan tidak terjadi masalah heterekesdositas.

\section{Analisis Kuantitatif}

Hasil Analisis Regresi Linear Berganda

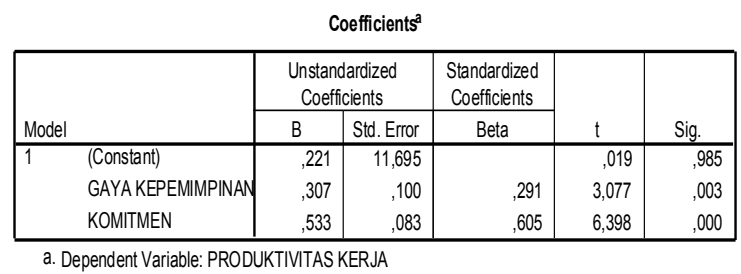

Persamaan regresi linear berganda sebagai berikut:

$$
\mathrm{Y}=0,019+3,077 \mathrm{X} 1+6,398 \mathrm{X} 2
$$


a. Konstanta sebesar 0,019, artinya jika tidak ada gaya kepemimpinan dan komitmen karyawan $\quad\left(\mathrm{X}_{1}=\mathrm{X}_{2}=0\right)$ maka nilai produktivitas kerja pegawai PT. Kunango Jantan. adalah sebesar konstanta yaitu 0,019 satuan. Dengan begitu sebelum dipengaruhi oleh variabel independen yang ada dalam penelitian ini nilai produktivitas kerja sudah ada sebesar 0,019. Akan tetapi nilai ini memperlihatkan hasil yang sangat kecil.

b. Koefisien gaya kepemimpinan adalah sebesar 0,221 artinya gaya kepemimpinan berpengaruh positif terhadap produktivitas kerja pegawai PT. Kunango Jantan. dimana jika kepemimpinan meningkat satu satuan maka produktivitas kerja pegawai akan meningkat sebesar 0,221 satuan.

c. Koefisien komitmen karyawan adalah sebesar 0,307 artinya komitmen karyawan berpengaruh positif terhadap produktivitas kerja pegawai PT. Kunango Jantan. dimana jika komitmen karyawan meningkat satu satuan maka produktivitas kerja pegawai akan meningkat sebesar 0,307 satuan.

\section{Koefisien Determinasi}

\section{Uji R Square}

Model Summary

\begin{tabular}{|l|r|r|r|r|}
\hline Model & \multicolumn{1}{|c|}{$\mathrm{R}$} & R Square & $\begin{array}{c}\text { Adjusted } \\
\text { R Square }\end{array}$ & $\begin{array}{r}\text { Std. Error of } \\
\text { the Estimate }\end{array}$ \\
\hline 1 &, $688^{\mathrm{a}}$ &, 474 &, 456 & 11,011 \\
\hline
\end{tabular}

a. Predictors: (Constant), KOMITMEN, GAYA KEPEMIMPINAN

Sumber : Lampiran Hasil Pengolahan Data, 2018
Nilai koefieisien determinasi PT. Kunango Jantan ditunjukan dengan nilai Adjust $R$ Square sebesar 0,456, hal ini berarti besarnya kontribusi pengaruh gaya kepemimpinan dan komitmen karyawan terhadap produktivitas kerja pegawai PT. Kunango Jantan. 71,4\% sedangkan sisanya $28,6 \%$ dipengaruhi oleh variabel lain seperti lingkungan kerja, insentif dan lainnya.

\section{Pengujian Hipotesis}

\section{Uji T}

\begin{tabular}{|c|c|c|c|c|c|c|}
\hline \multicolumn{7}{|c|}{ Coefficients ${ }^{a}$} \\
\hline \multirow[b]{2}{*}{ Model } & & \multicolumn{2}{|c|}{$\begin{array}{c}\text { Unstandardized } \\
\text { Coefficients }\end{array}$} & \multirow{2}{*}{$\begin{array}{c}\begin{array}{c}\text { Standardized } \\
\text { Coefficients }\end{array} \\
\text { Beta }\end{array}$} & \multirow[b]{2}{*}{$t$} & \multirow[b]{2}{*}{ Sig. } \\
\hline & & $B$ & Std. Error & & & \\
\hline & (Constant) & 221 & 11,695 & & 019 &, 985 \\
\hline & GAYA KEPEMIMPINAN & ,307 & 100 & 291 & 3,077 & 003 \\
\hline & KOMITMEN &, 533 & 083 & 605 & 6,398 &, 000 \\
\hline
\end{tabular}

a. Dependent Variable: PRODUKTIVITAS KERJA

\section{a Dependent Variable: EFEKTIVITAS}

KERJA

Berdasarkan uji t sebagai berikut :

1. Nilai thitung 3.077 dan nilai $(\mathrm{sig}=$ $0,003<0,05)$. Dengan df $=61-2=59$ diperoleh $t_{\text {tabel }}$ sebesar 1.671, dari hasil di atas dapat dilihat bahwa $t_{\text {hitung }}>$ $\mathrm{t}_{\text {tabel }}$ atau $3.077>1.671$, maka variabel gaya kepemimpinan berpengaruh signifikan terhadap produktivitas kerja pegawai PT. Kunango Jantan.

2. Nilai thitung 6.398 dan nilai ( $\mathrm{sig}=$ $0,005<0,05)$. Dengan df $=61-2=59$ diperoleh $t_{\text {tabel }}$ sebesar 1.671, dari hasil di atas dapat dilihat bahwa $t_{\text {hitung }}>$ $t_{\text {tabel }}$ atau $6.398>1.671$, maka variabel komitmen karyawan 
berpengaruh signifikan terhadap produktivitas kerja pegawai PT. Kunango Jantan.

\section{Uji F}

\section{Hasil Uji Kelayakan (Uji F)}

\begin{tabular}{|c|c|c|c|c|c|c|}
\hline \multicolumn{7}{|c|}{ ANOVA } \\
\hline \multicolumn{2}{|c|}{ Model } & $\begin{array}{l}\text { Sum of } \\
\text { Squares }\end{array}$ & $d f$ & Mean Square & $\mathrm{F}$ & Sig. \\
\hline \multirow[t]{3}{*}{1} & Regression & 6442,817 & 2 & 3221,409 & 26,570 &, $000^{\circ}$ \\
\hline & Residual & 7153,377 & 59 & 121,244 & & \\
\hline & Total & 13596,194 & 61 & & & \\
\hline
\end{tabular}

Berdasarkan uji $\mathrm{F}$ diketahui bahwa nilai $\mathrm{F}$ hitung 26.570 dengan nilai signifikansi sebesar $0,000(p<0,05)$. Hal ini berarti secara bersama-sama variabel gaya kepemimpinan dan komitmen karyawan berpengaruh signifikan bersama-sama terhadap produktivitas kerja pegawai PT. Kunango Jantan.

\section{Pembahasan}

Pengaruh Gaya Kepemimpinan Terhadap Produktivitas kerja

Nilai thitung 3.077 dan nilai $(\mathrm{sig}=$ $0,003<0,05)$. Dengan df $=61-2=59$ diperoleh $t_{\text {tabel }}$ sebesar 1.671, dari hasil di atas dapat dilihat bahwa $t_{\text {hitung }}>t_{\text {tabel }}$ atau $3.077>1.671$, maka variabel gaya kepemimpinan berpengaruh signifikan terhadap produktivitas kerja pegawai PT. Kunango Jantan.

Penelitian tentang Pengaruh berbagai variabel terhadap produktivitas kerja telah banyak dilakukan, yang dilakukan oleh Jana Susila (2014) ditemukan terdapat pengaruh gaya kepmimpinan terhadap produktivitas kerja Karyawan Pada Bagian Tenaga
Penjualan UD Surya Raditya Negara. Penelitian lain yang dilakukan oleh Lestari (2015 : 23-30) hasil penelitian menunjukkan bahwa gaya kepemimpinan berpengaruh terhadap produktivitas kerja karyawan.

Menurut Wahjosumidjo (2014:47) berdasarkan konsep dasar kepemimpinan, ada banyak gaya kepemimpinan seorang pemimpin. Dan, dari sekian gaya, salah satunya yang kita bahas dalam hal ini adalah gaya demokratis seorang pemimpin. Diakui bahwa pengaruh gaya kepemimpinan terhadap produktivitas kerja pada model ini sangat tinggi. Hal ini karena sang pemimpin bukan sebagai 'orang lain' bagi para pekerja. Dalam interaksi antar personil, pemimpin dan anak buah berada pada satu kondisi yang saling membutuhkan dan menguntungkan. Dengan demikian gaya kepemimpinan berkontribusi terhadap produktivitas kerja seorang pegawai.

Banyak faktor yang mempengaruhi produktivitas kerja karyawan salah satunya gaya kepemimpinan dan komitmen karyawan. Peran pemimpin disuatu organisasi sangat dominan meskipun demikian seorang pemimpin tidak boleh mengabaikan peranan pekerja sebagai pelaksana berbagai macam pekerjaan dan tugas untuk mencapai tujuan perusahaan. Untuk itu seorang pemimpin harus terus menerus mendorong dan memotivasi karyawan sehingga karyawan dapat berprestasi. Kemepimpinan yang efektif sangat penting untuk kelangsungan hidup dan keberhasilan sebuah organisasi

\section{Pengaruh Komitmen Karyawan terhadap Produktivitas kerja}

Nilai thitung 6.398 dan nilai $(\mathrm{sig}=$ $0,005<0,05)$. Dengan $\mathrm{df}=61-2=59$ diperoleh $t_{\text {tabel }}$ sebesar 1.671, dari hasil di atas dapat dilihat bahwa $t_{\text {hitung }}>t_{\text {tabel }}$ atau $6.398>1.671$, maka variabel komitmen karyawan berpengaruh signifikan terhadap 
produktivitas kerja pegawai PT. Kunango Jantan.

Penelitian oleh Jana Susila (2014) ditemukan terdapat pengaruh komitmen karyawan berpengaruh terhadap produktivitas kerja Pada Bagian Tenaga Penjualan UD Surya Raditya Negara. Penelitian lain yang dilakukan oleh Lestari (2015 : 23-30) hasil penelitian menunjukkan bahwa komitmen karyawan berpengaruh terhadap produktivitas kerja.

Menurut Sapeni (2013:88) tinggi rendahnya komitmen karyawan tentu ada faktor yang mempengaruhi terhadap hal demikian, komitmen karyawan selain tumbuh rasa kepedulian seseorang terhadap suatu tugas dan kepentingan umum dan organisasi, bukan saja karena atas kepentingan pribadi, akan memberi kontribusi terhadap komitmen. Komitmen karyawan terhadap organisasi terdiri-dari komitmen efektif, komitmen berkelanjutan dan komitmen normatif.

Pengaruh Gaya Kepemimpinan dan Komitmen Karyawan Secara BersamaSama terhadap Produktivitas kerja

Berdasarkan uji $\mathrm{F}$ diketahui bahwa nilai $F$ hitung 26.570 dengan nilai signifikansi sebesar $0,000(\mathrm{p}<0,05)$. Hal ini berarti secara bersama-sama variabel gaya kepemimpinan dan komitmen karyawan berpengaruh signifikan bersama-sama terhadap produktivitas kerja pegawai PT. Kunango Jantan.

Penelitian tentang Pengaruh berbagai variabel terhadap produktivitas kerja telah banyak dilakukan, yang dilakukan oleh Jana Susila (2014) mengenai Pengaruh kepemimpinan dan budaya kerja terhadap produktivitas kerja Karyawan Pada Bagian Tenaga Penjualan UD Surya Raditya Negara. Hasil penelitiannya menunjukkan bahwa secara simultan dan parsial gaya kepemimpinan dan komitmen organisasi berpengaruh terhadap produktivitas kerja.
Penelitian lain yang dilakukan oleh Lestari (2015 : 23-30) yang meneliti tentang Pengaruh Gaya Kepemimpinan Terhadap produktivitas kerja Karyawan (Studi Pada Koperasi Pegawai Negeri). Hasil penelitian menunjukkan bahwa secara simultan dan parsial gaya kepemimpinan berpengaruh terhadap produktivitas kerja karyawan.

Pada bahagian lain Discenza dan Smith dalam Fathony (2013:32) mengemukakan bahwa faktor-faktor umum yang mempengaruhi produktivitas kerja meliputi dimensia Individu (yaitu kemampuan, prestasi, motif, sasaran, kebutuhan dan nilai) ; suasana motivasi dan kompensasi, kepuasan kerja, komitmen kerja, kemimpinan, demensia kelompok (yaitu, status, norma, keeratan dan iklim komunikasi serta struktur perusahaan termasuk unsur-unsur makro dalam pengendalian dan perencanaan).

\section{KESIMPULAN DAN SARAN}

\section{Kesimpulan}

Berdasarkan hasil penelitian maka dapat ditarik kesimpulan sebagai berikut :

1. Variabel gaya kepemimpinan berpengaruh positif signifikan terhadap produktivitas kerja pegawai PT. Kunango Jantan dikarenakan nilai $(\operatorname{sig}=0,003<0,05)$.

2. Variabel komitmen karyawan berpengaruh positif signifikan terhadap produktivitas kerja pegawai PT. Kunango Jantan dikarenakan nilai $(\mathrm{sig}=0,000<0,05)$.

3. Secara bersama-sama variabel gaya kepemimpinan dan komitmen karyawan berpengaruh bersama- 
sama terhadap produktivitas kerja pegawai PT. Kunango Jantan.

4. Kontribusi paling besar berpengaruh terhadap produktivitas kerja karyawan adalah komitmen karyawan yaitu sebesar $60,5 \%$.

\section{Saran}

1. Sebaiknya perusahaan menciptakan gaya kepemimpinan yang menyenangkan agar tercapai produktivitas kerja pegawai yang tinggi.

2. Bagi Universitas Ekasakti dapat dijadikan tambahan literatur mengenai pengaruh gaya kepemimpinan dan komitmen karyawan terahdap produktivitas kerja pegawai dalam bekerja.

3. Bagi peneliti selanjutnya dapat dijadikan sebagai literatur dalam meneliti topik yang sama dengan variabel yang berbeda.

\section{DAFTAR PUSTAKA}

Alex. 2014. Komitmen Erlangga. Jakarta.

Arikunto. 2013. Metodelogi Penelitian. Jakarta.Rieneka Cipta

Fathony. 2013. Marketing Managemen. New Jersey. Prentice Hall. International Inc.

Ghozali, 2013. Aplikasi Analisis Multivariat dengan SPSS.Semarang: Universitas Diponegoro.
Hasri, Salfen. 2013. Sekolah Efektif dan Guru Efektif, Makasar. Yayasan Pendidikan Makasar BTN Minasa Upa N3/16.

Hendri. 2013. Kinerja Dan Pengembangan Kompetensi SDM, Yogyakarta: Pustaka Pelajar

Idris. 2014. Analisis Data Kuantitatif. UNP Padang.

Mangkunegara. 2015. Perilaku dan Budaya Organisasi. Rafika Aditama. Bandung.

Pasolong, Harbani. 2013. Kepemimpinan Biroktasi. Bandung: Alfabeta

Prokopenko, Joseph. 2014. Productivity Manajemen A. Practical Handbook. Ganeva : ILO

Rivai. 2014. Manajemen Sumber Daya Manusia untuk Perusahaan: Dari Teori ke Praktik (Edisi 3). PT. Pustaka Gramedia Utama. Jakarta

Robbins. 2013. Organizatioan Behavior, Sixth Edition, Singapore: MCGraw Hill Book Co.

Sapeni.2013. Manajemen Sumber Daya Manusia. CV Alfabeta. Bandung.

Sembiring. 2013. Budaya dan Kinerja Organisasi. Fokus Media. Bandung.

Siagian. 2013. Organisasi, Kepemimpinan dan Prilaku Administrasi. Jakarta : Gunung Agung.

Sugiyono. 2013. Statistika Untuk Penelitian. Bandung: CV. Alfabeta

Sinungan, $\quad 2013$. Produktivitas apa dan Bagaimana. Jakarata: Bumi Aksara. 
Sutrisno, 2013. Produktivitas. Bumi Aksara. Jakarta.

Timpe. 2014. Memotivasi Pegawai, Terjemahan Susanto Budhiharmo. Jakarta : Alex Media Komputindo

Umar. 2013. Metodologi Penelitian Bisnis. Bandung; Alphabeta

Wahjosumidjo. 2014. Kepemimpinan dan Motivasi. Jakarta: Ghalia Indonesia.

Wibowo, 2014. Manajemen Kinerja, Jakarta: PT Raja Grapindo Persada.

Winardi. 2012, Motivasi dan Pemotivasian Dalam Manajemen. Jakarta, Raja Grafindo Persada.

Wirawan. 2013. Budaya dan Iklim

Organisasi. Salemba Empat. Jakarta. 